\title{
Growth Factors in Wound Healing Single and Synergistic Effects on Partial Thickness Porcine Skin Wounds
}

\author{
Samuel E. Lynch, ${ }^{\star}$ Robert B. Colvin, ${ }^{\ddagger}$ and Harry N. Antoniades \\ *Department of Periodontics, Harvard School of Dental Medicine, and Institute of Molecular Biology, Boston, Massachusetts 02115; \\ ${ }^{\ddagger}$ Department of Pathology at Harvard Medical School, and Immunopathology Unit, Massachusetts General Hospital, Boston, \\ Massachusetts 02114; and $\$$ Department of Nutrition, Harvard School of Public Health, Boston, Massachusetts 02115
}

\begin{abstract}
Several growth factors are potential mediators of wound healing, although their actual roles, interactions, and therapeutic use are not established. Six well-characterized human growth factors were chosen for detailed investigation by topical application to standardized skin wounds in swine: epidermal growth factor (EGF), transforming growth factors $\alpha$ and $\beta$ (TGF- $\alpha$ and TGF- $\beta$ ), fibroblast growth factor (FGF), insulin-like growth factor-I (IGF-I), and platelet-derived growth factor (PDGF). When applied singly in doses up to 1,500 ng, only TGF- $\beta$ produced a marked tissue response, as demonstrated by an increase in the new connective tissue volume, the collagen content and maturity, and increased angiogenesis. However, TGF- $\beta$ enhanced inflammation and caused abnormal epithelial differentiation and decreased epithelial volume, the last reversed by addition of IGF-I. Recombinant PDGF-2 homodimer, if given in combination with recombinant IGF-I, caused a similar increase in the new connective tissue volume and collagen content and maturity, but without increased inflammation. In addition, this combination stimulated increased amounts of epithelium with normal differentiation. The synergy of PDGF-2 and IGF-I was optimal at a ratio of 2:1 by weight. Of the six individual factors and nine combinations tested, the combinations of PDGF-2 and IGF-I or PDGF-2 and TGF- $\alpha$ were the most potent stimulators of healing in the absence of increased inflammation.
\end{abstract}

\section{Introduction}

Polypeptide growth factors are a class of biological mediators that promote cell proliferation, alone or in concert, by binding to specific cell surface receptors. Molecules classified as growth factors may have additional potent and diverse effects on cell differentiation, motility, and matrix synthesis. These properties, demonstrable in vitro, have led to the proposal that such growth factors play important roles in wound healing. Indeed, platelet-derived growth factor (PDGF), ${ }^{1}$ insulin-like growth

Address reprint requests to Dr. S. E. Lynch, Department of Periodontics, Harvard School of Dental Medicine, 188 Longwood Avenue, Boston, MA 02115.

Received for publication 15 August 1988 and in revised form 21 December 1988.

1. Abbreviations used in this paper: EGF, epidermal growth factor; FGF, fibroblast growth factor; IGF-I, insulin-like growth factor-I; PDGF, platelet-derived growth factor; TGF, transforming growth factor.

J. Clin. Invest.

(c) The American Society for Clinical Investigation, Inc. 0021-9738/89/08/0640/07 \$2.00

Volume 84, August 1989, 640-646 factor (IGF), transforming growth factor (TGF)- $\beta$, TGF- $\alpha$, epidermal growth factor (EGF), and fibroblast growth factor (FGF) have each been reported to accelerate formation of various components in healing wounds.

PDGF is a potent mitogen, chemotactic agent, and stimulator of protein synthesis for cells of mesenchymal origin. PDGF is stored in the alpha granules of circulating platelets and is released at wound sites during blood clotting; later it may be synthesized locally by infiltrating macrophages $(1,2)$. IGF-I acts in combination with PDGF to promote mitogenesis and protein synthesis in mesenchymal cells in culture $(3,4)$. In previous studies topical application of PDGF from human platelets or recombinant IGF-I to partial thickness skin wounds alone did not significantly enhance the repair process $(5,6)$, although when combined these factors did promote connective tissue and epithelial growth (6).

TGF- $\beta$ stimulates or inhibits the growth of many cell types, depending upon the presence of other growth factors and is a potent chemoattractant for macrophages $(7-10)$. TGF- $\beta$ is stored in the alpha granules of platelets and synthesized by many cell types in vitro, including macrophages. Addition of TGF- $\beta$ in vivo increases granulation tissue formation and the tensile strength of healing dermal wounds $(11,12)$. FGF, a polypeptide extracted from the brain, pituitary gland, and other organs stimulates DNA and protein synthesis in mesenchymal and endothelial cells in culture. In vivo FGF promotes angiogenesis and granulation tissue formation (13-15). TGF- $\alpha$ is related to EGF and may interact with the same receptors on epithelial cells to stimulate mitogenesis (16). TGF- $\alpha$ is made by normal and transformed cells in vitro and EGF is present in salivary and gastric secretions. Both TGF- $\alpha$ and EGF accelerate reepithelialization of skin wounds (17-20). Sustained release of EGF increases granulation tissue formation in subcutaneous sponge implants (21).

Although the isolated reports described above demonstrate that these growth factors alter wound healing processes, the conclusions that can be drawn are limited because of the heterogeneity of the models used and lack of direct comparisons of multiple factors or combinations of factors. We report here on the responses to each of these growth factors alone and in combination with one another in a well defined skin wound healing model.

\section{Methods}

Analysis of growth factors. The growth factors used in these studies included recombinant c-sis/PDGF-2 (BB) homodimer (PDGF, Inc., Boston, MA), IGF-1 and EGF (AmGen Biologicals, Thousand Oaks, CA), basic FGF (R\&D Systems, Minneapolis, MN), synthetic TGF- $\alpha$ (Peninsula Laboratories, Belmont, CA), and TGF- $\beta$ isolated from human and porcine platelets (R\&D Systems, Minneapolis, MN). All growth factors were greater than $90 \%$ pure by polyacrylamide gel elec- 
trophoresis. Biologic activity was measured by $\left[{ }^{3} \mathrm{H}\right]$ thymidine incorporation into $\mathrm{BALB} / \mathrm{c} 3 \mathrm{~T} 3$ fibroblasts under serum depleted conditions (22); half maximal activity was reached at $1.5 \mathrm{ng} / \mathrm{ml}$ of platelet-derived growth factor (PDGF)-2 and at $2.0 \mathrm{ng} / \mathrm{ml}$ of basic FGF. IGF-I and EGF were inactive under serum-depleted conditions. Preincubation of 3T3 fibroblasts with PDGF (23) yielded half-maximal stimulation by IGF-I at $2.7 \mathrm{ng} / \mathrm{ml}$ and by EGF at $3.5 \mathrm{ng} / \mathrm{ml}$. TGF- $\alpha$ yielded halfmaximal stimulation of BALB/MK cells at $0.35 \mathrm{ng} / \mathrm{ml}$ (24); TGF- $\beta$ at $1 \mathrm{ng} / \mathrm{ml}$ caused a $50 \%$ reduction of DNA synthesis in these cells.

Wound healing model. Partial thickness wounds $(10 \times 15 \mathrm{~mm})$ were surgically induced in the back and thoracic areas of young white Yorkshire pigs as previously described (6). Growth factors were brought to physiologic $\mathrm{pH}$ using $\mathrm{PBS}, \mathrm{pH} 7.4$, and incorporated into a $3 \%$ methyl cellulose gel, which served as an inert carrier. All factors were applied once topically onto the wound site within $45 \mathrm{~min}$ after wounding; $125-1,500 \mathrm{ng}$ of each growth factor in $30 \mu \mathrm{l}$ of the gel were applied to each wound. This range has been shown to give optimal results using human PDGF plus IGF-I (6). "Checkerboard" experiments were also performed with PDGF-2 and IGF-I in which the amount of either component was held constant and the amount of the other varied.

After a single application of the polypeptide factors, the wounds were covered with a semiocclusive dressing (Tegaderm; 3M, St. Paul, MN) which remained in place for the duration of the experiments. The animals were placed in a sling (Chathum Medical Arts, Los Angeles, CA) for $\sim 24 \mathrm{~h}$ following surgery, during which time they received intravenous pentabarbital. Complete excisional biopsies were obtained 7 and $10 \mathrm{~d}$ following wounding. From the center of the biopsy specimen three $1.5-\mathrm{mm}$ wide cross-sections were removed and frozen in liquid nitrogen. The remaining two halves of the wound were fixed in fresh $10 \%$ buffered formalin and standard processing and paraffin embedding procedures followed. Computer aided morphometric analysis was performed on coded hematoxylin and eosin and Masson trichrome stained $4-\mu \mathrm{m}$ sections to determine the cross-sectional area of the newly synthesized epidermal and dermal layers. The mean thickness of the newly synthesized tissues was calculated by dividing the cross-sectional area of the epidermis and dermis by the width of the wound measured. The epidermal-dermal interface area was calculated by measuring the perimeter of the epithelium per cross section (less the outer surface and cut edges) and multiplying by the length of the wound $(15 \mathrm{~mm})$. The dermal cellularity was quantitated using an ocular grid to determine cells $/ \mathrm{mm}^{2}$ in the new connective tissue then multiplying by the thickness of the dermis to give cells/linear millimeter.

Hydroxyproline content was determined in the $1.5-\mathrm{mm}$ wide frozen cross sections by separating the newly formed wound tissue from the remaining tissue under a dissecting microscope. The wound tissue was hydrolyzed in $6 \mathrm{M} \mathrm{HCl}$ overnight at $120^{\circ} \mathrm{C}$ and hydroxyproline analyses were performed on the hydrolysate as described previously (25). Results were converted to whole wound values by multiplying by 10. All values are expressed above control (gel plus PBS) levels. The mean and standard deviation were calculated for each group and significance determined by the Student's $t$ test.

\section{Results}

$P D G F-2$ and IGF-I. Of all treatment modalities tested, only the combination of PDGF-2 plus IGF-I produced a significant increase above control levels in the mean thickness of the newly synthesized epidermis $7 \mathrm{~d}$ after wounding (94\%, $P$ $<0.002$, Fig. $1 A$ and Fig. $2 D$ ). The increase in epithelial thickness was accompanied by an increase in the number and depth of epithelial extensions within the dermis that resulted in an increased epidermal-dermal interface area $(102 \% P$ $<0.002$, Fig. $1 B$ ). The effect on the epidermis was less evident at $10 \mathrm{~d}$ when the thickness was $36 \%$ greater than controls $(P$
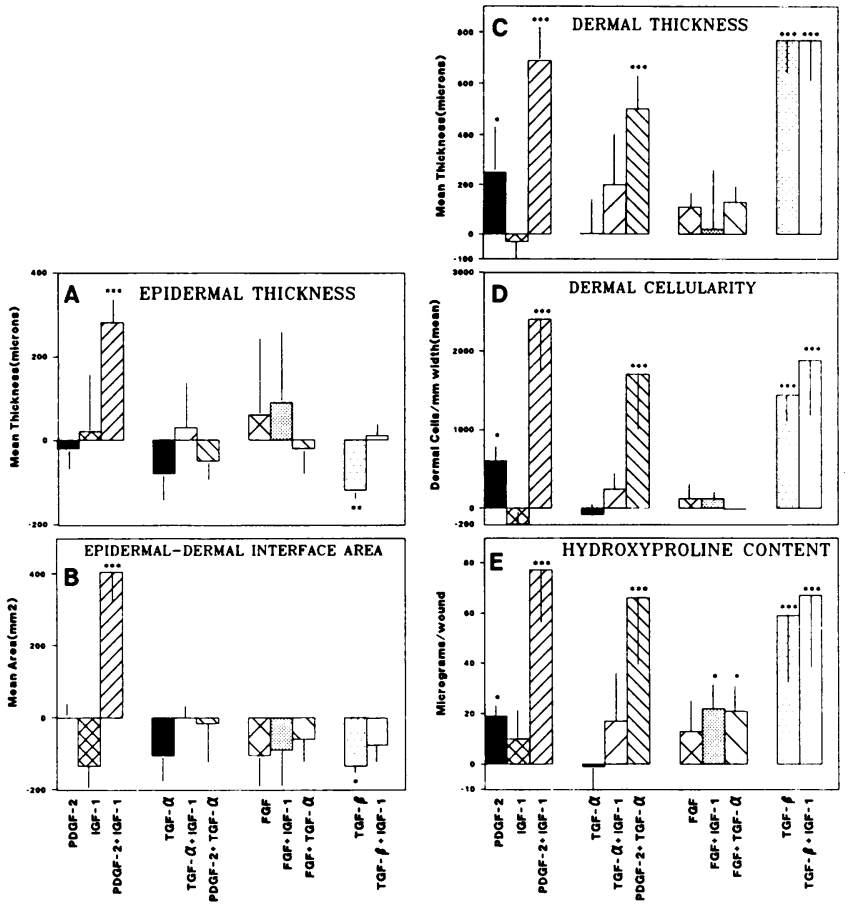

Figure 1. Morphometric and hydroxyproline analyses of 7-d-old wounds. A single application of $500 \mathrm{ng}$ of each growth factor was administered topically to $10 \times 15 \mathrm{~mm}$ partial thickness porcine skin wounds. Control values are $(A) 278 \pm 84 \mu \mathrm{m},(B) 405 \pm 87 \mathrm{~mm}^{2},(C)$ $514 \pm 98 \mu \mathrm{m},(D) 805 \pm 110$ cells $/ \mathrm{mm}$ width, $(E) 26.9 \pm 9.7 \mu \mathrm{g} /$ wound. $n=6$ wounds for all tests except PDGF plus IGF-I where $n=15$ (mean $\pm 1 \mathrm{SD},{ }^{*} P<0.05,{ }^{* *} P<0.005,{ }^{* * *} P<0.002$ ).

$<0.05$, Fig. $3 \mathrm{D}$ ) and there were fewer extensions of epithelium at this time. PDGF-2 or IGF-I alone did not have a significant effect on epidermal thickness (Fig. $1 A$, Fig. 2, $A-C$, and Fig. 3, $A-C$ ).

The thickness of the newly synthesized dermis was not significantly affected by the addition of IGF-I alone, but PDGF-2 alone did cause a $64 \%$ increase above controls in dermal thickness $(P<0.05$, Fig. $1 C)$. The combination of PDGF-2 plus IGF-I resulted in a $132 \%$ increase in the dermal thickness $(P<0.002$, Fig. $1 C)$ and a $300 \%$ increase in the number of connective tissue cells within the wound site $(P$ $<0.002$, Fig. $1 \mathrm{D}$ ). PDGF-2-treated wounds had a loosely arranged disorganized collagen matrix, while wounds treated with PDGF-2 and IGF-I exhibited an increased organization and maturation of the collagen fibers (Fig. 2, $A-D$ ). The number of inflammatory cells was not increased appreciably in any wounds receiving PDGF-2 and/or IGF-I (Fig. 2, $B-D$ ). At $10 \mathrm{~d}$ the connective tissue was still increased to $141 \%$ of control thickness $(P<0.002$, Fig. 3$)$ and the number of cells in the connective tissue remained elevated $(170 \%, P<0.002)$.

Analysis of the wound tissue for hydroxyproline revealed that the increase in hydroxyproline content in wounds correlated with the histologic appearance of increased collagen formation. Addition of PDGF-2 alone and in combination with IGF-I produced a $68 \%(P<0.05)$ and $283 \%(P<0.002)$ increase, respectively, in hydroxyproline content within the wound site (Fig. $1 E$ ). Quantities of PDGF-2 and IGF-I were varied to determine the optimum ratios for the synergism as judged by increased hydroxyproline levels (Fig. 4). In the pres- 


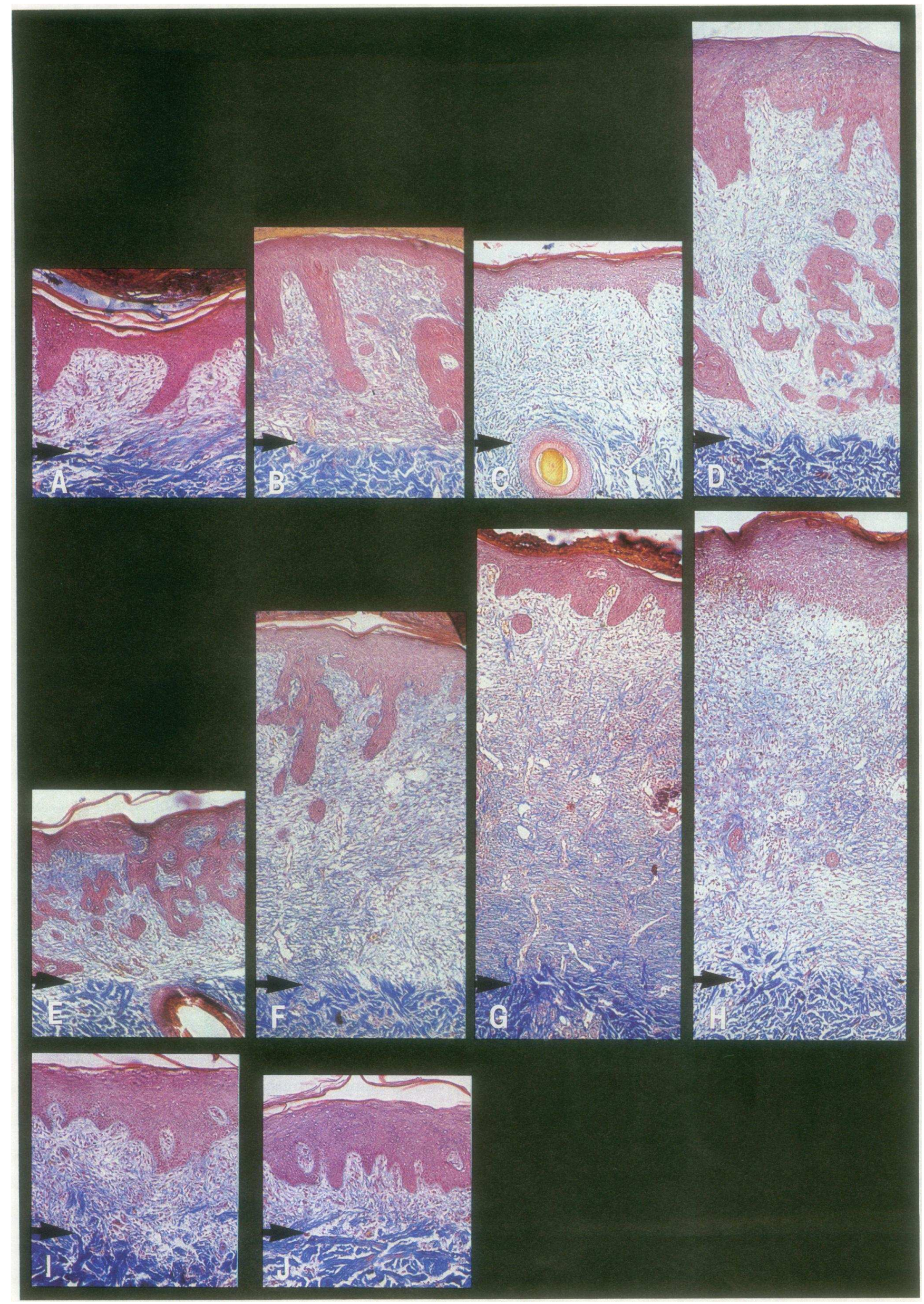




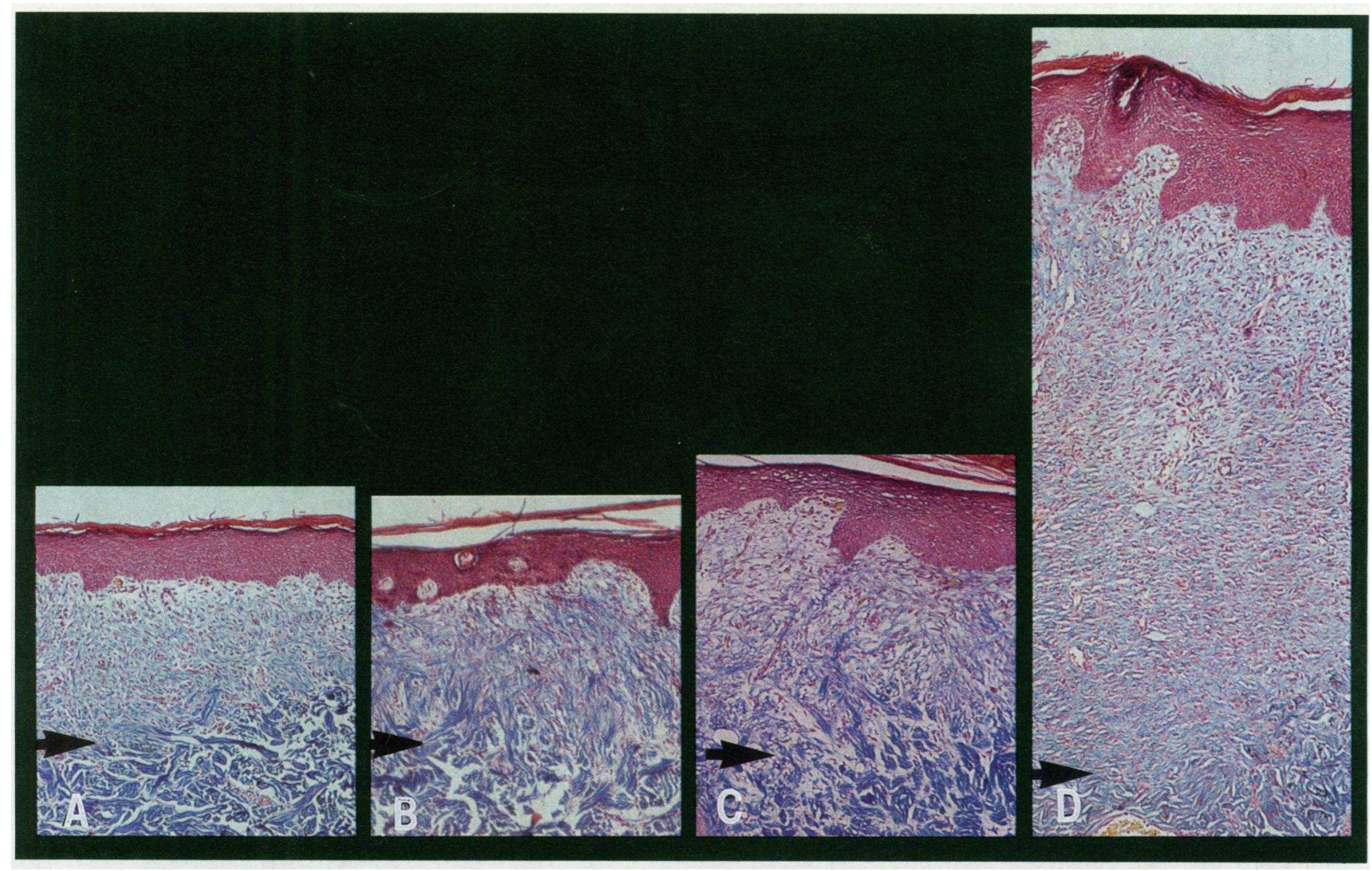

Figure 3. Histologic appearance of 10-d-old wounds. All wounds received a single 500-ng application of each growth factor after wounding: $(A)$ PBS, (B) IGF-I, (C) PDGF-2, (D) PDGF-2 plus IGF-I (Masson Trichrome; $\times 16$ ).

ence of $500 \mathrm{ng}$ of IGF-I, the response to PDGF-2 increased progressively to the highest dose tested $(500 \mathrm{ng})$. When the dose of PDGF-2 was held constant to $500 \mathrm{ng}$, the maximum response occurred with a dose of $250 \mathrm{ng}$ of IGF-I. Thus the optimal ratio of PDGF-2:IGF-I was $2: 1$ by weight (1:2 molar ratio).

$T G F-\alpha$. TGF- $\alpha$ alone or in combination with IGF-I caused an increase in the size of the basal epidermal cells (hypertrophy) with premature keratinization and pyknosis (dyskeratosis, Fig. $2 E$ ). The thickness of the epithelium was unchanged and no response was detected in the connective tissue (Fig. 1, $A-E$ ). However, if PDGF-2 was applied in combination with TGF- $\alpha$, there was a significant increase $(94 \%)$ in the thickness of the new connective tissue and a $150 \%$ increase in the number of cells in the connective tissue, without increased inflammation (both $P<0.002$, Fig. 1, $C$ and $D$ ). The combination of PDGF-2 and TGF- $\alpha$ caused a $246 \%$ increase in hydroxyproline content $(P<0.002$, Fig. $1 E)$. The collagen fibers were only occasionally highly oriented but were quite dense, especially near the base of the wound (Fig. $2 F$ ).

$E G F$ and $F G F$. At the concentrations tested, neither basic FGF nor EGF alone produced significant changes in any parameters measured, although FGF-treated wounds did show a tendency to have an increased epidermal thickness and hydroxyproline content (Fig. $1, A$ and $E$, Fig. 2, $I$ and $J$ ). The combination of FGF with either IGF-I or TGF- $\alpha$ produced a modest, but significant increase in the hydroxyproline content (76\% increase, $P<0.05$, Fig. $1 E$ ). The combinations of PDGF-2 plus EGF, PDGF-2 plus FGF, and FGF plus EGF did not produce statistically significant changes in the parameters measured (data not shown), although the combination of FGF and EGF did cause hypertrophy of basal epidermal cells and dyskeratosis.

$T G F-\beta$. TGF- $\beta$ treated wounds had a $40 \%$ decrease in the thickness of the new epidermis $(P<0.005$, Fig. $1 A)$ and dyskeratosis was evident. The addition of IGF-I to TGF- $\beta$ restored epidermal thickness to control levels but had no effect on the dyskeratosis (Fig. 5). TGF- $\beta$ produced a $148 \%$ increase in the newly synthesized dermal layer and a $101 \%$ increase in the number of fibroblasts within the wound site (both $P$ $<0.002$, Fig. 1, $C$ and $D$ ). Addition of IGF-I did not change the connective tissue responses.

Wounds receiving TGF- $\beta$ alone contained more organized mature (polarizable) collagen fibers near the base than control wounds (Fig. 2, $G$ and $H$ ). In wounds treated with TGF- $\beta$ plus IGF-I the mature collagen fibers were more uniformly distrib-

Figure 2. Histologic appearance of 7-d-old skin wounds. The wounds were treated immediately after wounding with a single 500-ng application of: Top row $(A)$ PBS, $(B)$ IGF-I, $(C)$ PDGF-2, $(D)$ PDGF-2 plus IGF-I. Middle row, $(E)$ TGF- $\alpha,(F)$ TGF- $\alpha$ plus PDGF-2, $(G)$ TGF- $\beta$, $(H)$ TGF- $\beta$ plus IGF-I. Bottom row, $(I)$ FGF, $(J)$ FGF plus IGF-I. Note that the base of the original wounds (arrows) have been aligned (Masson Trichrome; $\times 16)$. 


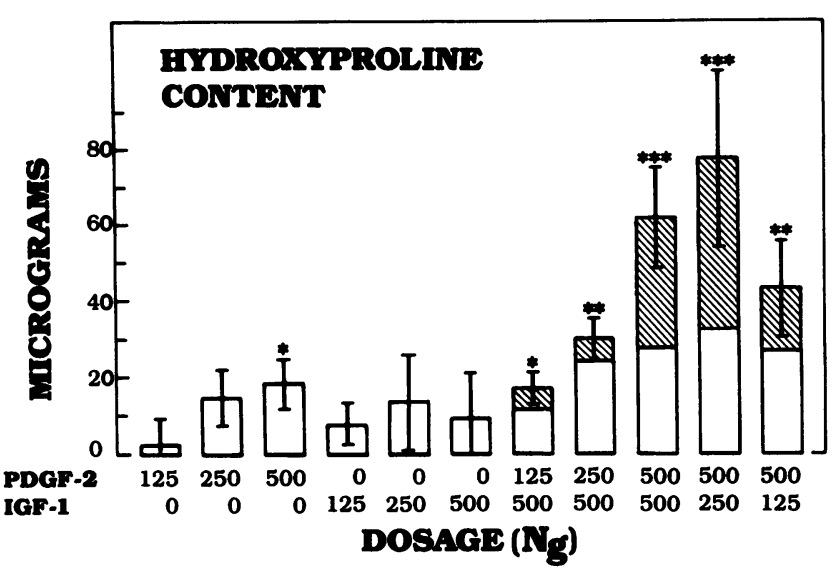

Figure 4. Checkerboard titration of PDGF-2 and IGF-I. Various concentrations $(0-500 \mathrm{ng})$ of each factor were applied to determine the optimum ratio for stimulating collagen formation in $10 \times 15-\mathrm{mm}$ partial thickness wounds. Total excisional biopsies were taken $7 \mathrm{~d}$ after wounding and hydroxyproline content measured. All values are expressed as the increase above control levels ( $24.9 \mu \mathrm{g} /$ wound, $n=9$ wounds, mean $\left.\pm 1 \mathrm{SD},{ }^{*} P<0.05,{ }^{* *} P<0.01,{ }^{* * *} P<0.005\right)$.

uted throughout the new connective tissue. The hydroxyproline content was increased $213 \%$ in TGF- $\beta$-treated wounds and $253 \%$ in TGF- $\beta$ plus IGF-I-treated wounds (both $P$ $<0.002$, Fig. $1 E$ ).

TGF- $\beta$-treated wounds (with or without IGF-I) also exhibited a marked increase in mononuclear inflammatory cells and in blood vessel formation (Fig. 2, $G$ and $H$ ). Increased angiogenesis was observed histologically and was visually evident as an increased erythema of the wounds. The mononuclear cells were evenly distributed throughout the new connective tissue and were often found inside vessels. The mononuclear cells

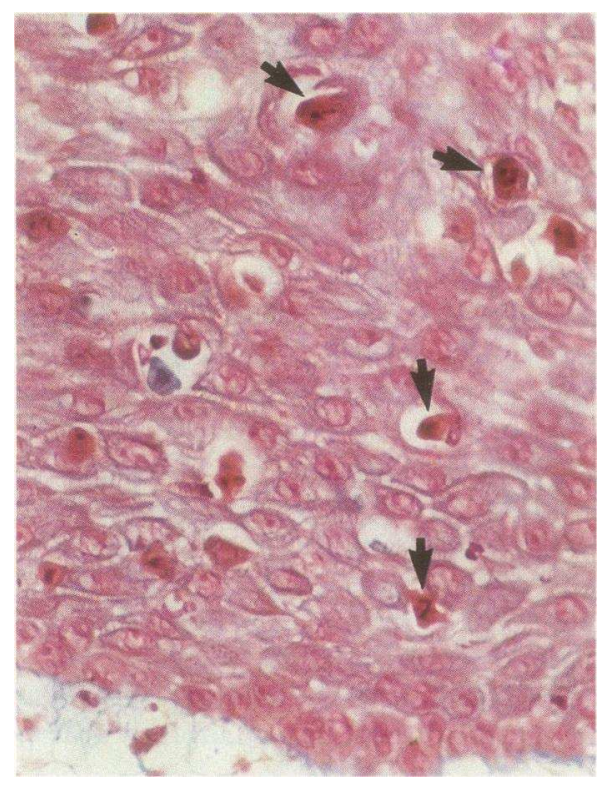

Figure 5. Dyskeratosis in TGF- $\beta$ plus IGF-I treated wound. Multiple dyskeratotic epithelial cells (arrows) were present in wounds treated with TGF- $\beta$, with and without IGF-I or TGF- $\alpha$ (Masson Trichrome; $\times 64)$. were typical macrophages, as judged by their abundant eosinophilic cytoplasm and rounded shapes.

\section{Discussion}

In these studies we compared the effects of six well-characterized growth factors in wound healing, using comprehensive and quantitative methods of analysis. The data demonstrate that application of single factors, such as PDGF, IGF-I, EGF, and FGF had little or no effect on the regeneration of connective tissue or epithelium in these standardized wounds. However, a combination of recombinant PDGF-2 homodimer with recombinant IGF-I produced a dramatic increase in connective tissue regeneration and epithelialization. This response was more than would be predicted from the sum of the effects of the individual factors and indicate a synergism that resulted in a four-fold increase in collagen synthesis and a doubling of dermal and epidermal thickness. TGF- $\alpha$ was able to substitute for IGF-I by acting synergistically with PDGF to promote collagen synthesis and fibroblast proliferation. However, the PDGF/TGF- $\alpha$ combination promoted only a variable increase in epithelial thickness. Indeed, abnormal differentiation, characterized by dyskeratosis was observed in most TGF- $\alpha$-treated wounds. FGF, alone or in combination with PDGF, IGF-I, or TGF- $\alpha$ did not stimulate as pronounced an effect as PDGF/ IGF-I or PDGF/TGF- $\alpha$ in the wound healing model used in our studies.

Of all the factors, the individual factor that stimulated the greatest response was TGF- $\beta$, which promoted a significant increase in collagen synthesis and fibroblast proliferation. These TGF- $\beta$ effects are consistent with previous observations made in other wound healing models $(9-12)$. However, the present studies also revealed that TGF- $\beta$ causes abnormal keratinocyte differentiation and inhibits epithelial cell growth, analogous to its effects in vitro $(26,27)$. In our studies inhibition of epithelial growth in vivo was reversed by the addition of IGF-I.

A notable feature of TGF- $\beta$ treated wounds was an accumulation of mononuclear phagocytes. This inflammatory response is probably a direct effect of TGF- $\beta$ on monocytes, as TGF- $\beta$ is a potent chemoattractant for monocytes in vitro (8). Indeed, some of the effects of TGF- $\beta$ on connective tissue regeneration and neovascularization may well be secondary to mediators produced by the infiltrating mononuclear phagocytes. Evidence for this hypothesis is that macrophages produce substantial amounts of an angiogenic factor (28) and that TGF- $\beta$ inhibits endothelial cells in vitro (29). Whatever the reason, neovascularization is an important process in the healing of most wounds and its increase in TGF- $\beta$-treated sites no doubt contributes to the potent connective tissue response elicited by this growth factor. However, the diverse effects of increased mononuclear infiltration are not well characterized. In contrast, wounds treated with PDGF alone, or in combination with IGF-I exhibited minimal inflammation and no significant increase in the presence of mononuclear cells. This lack of an inflammatory effect by the PDGF/IGF-I combination is supported by recent studies that demonstrate that pure PDGF derived from platelets or recombinant PDGF-2 are not chemoattractant for monocytes (30).

Enhancement of connective tissue regeneration by the PDGF/IGF-I combination in vivo is not surprising. As shown 
by in vitro studies the coordinate effect of PDGF, IGF-I and plasma from hypophysectomized rats was necessary for optimal DNA synthesis in cultured fibroblasts $(3,4)$. The coordinate effect of the two growth factors also produced maximal effects in vivo as judged by collagen synthesis and fibroblast proliferation at the site of the wound. On the other hand, the mechanism by which the PDGF-2/IGF-I combination stimulated epidermal growth is not known. The combination of PDGF-2/IGF-I does not synergistically stimulate mitogenesis of epithelial cells in culture. Indeed, there is a consensus that epithelial cells do not have membrane surface receptors for PDGF. It is possible that in vivo the combination of PDGF-2/ IGF-I stimulated the production of an epithelial cell growth factor by the proliferating fibroblasts. It is also possible that the connective tissue regeneration induced by these factors provided a matrix environment that enhanced epithelial cell proliferation. It is potentially important to note that the PDGF-2/ IGF-I combination altered the form, as well as the amount of connective tissue, as indicated by increased collagen fiber alignment and polarizability, features characteristic of more mature type I collagen. This, in turn, may alter the growth of the epithelium.

The factors in this study were added simultaneously so that their coordinate effects could be studied. It may also be interesting to examine the effects produced by sequential addition of these factors. However, the data presented here indicate that the coordinate effect of a combination of growth factors is necessary for maximal tissue response. Our previous studies have shown that a combination of PDGF derived from human platelets and IGF-I was effective in stimulating both connective tissue and epithelial cell regeneration in wounds in animals. The present studies demonstrated for the first time that recombinant PDGF-2 in combination with recombinant IGF-I has similar effects at identical concentrations. The results further demonstrate that, of the individual growth factors and combinations tested, PDGF-2 plus IGF-I or PDGF-2 plus TGF- $\alpha$ appear to be the most potent inducers of wound healing in the absence of increased inflammation. The ability to demonstrate the effectiveness of recombinant PDGF-2 in a wound healing model is significant because its increased safety and availability makes clinical evaluation feasible.

\section{Acknowledgments}

The authors also wish to thank Dr. James Southern for aid in the morphometric analyses. The handling of the animals used in these studies was in accordance with established guidelines at the Harvard School of Public Health. Animals were anesthetized during surgical procedures using ketamine $(30 \mathrm{mg} / \mathrm{kg}$ i.m.), atropine $(0.05 \mathrm{mg} / \mathrm{kg}$ i.m.), and xylazine $(2.0 \mathrm{mg} / \mathrm{kg}$ i.m.), and sodium pentabarbital (1.67 $\mathrm{mg} / \mathrm{kg}$ i.v.).

Supported by funds from the Institute of Molecular Biology and National Institutes of Health grant R37-CA 20822 (R. B. Colvin).

\section{References}

1. Antoniades, H. N., and A. J. Owen. 1984. Human platelet-derived growth factor. In Hormonal Proteins and Peptides. C. H. Li, editor. Vol. 7. Academic Press, Inc., New York. 231-277.

2. Ross, R. 1987. Platelet-derived growth factor. Annu. Rev. Med. 38:71-79.
3. Van Wyk, J. J. 1984. The somatomedins: biological actions and physiologic control mechanisms. In Hormonal Proteins and Peptides. C. H. Li, editor. Vol. 12. Academic Press, Inc., New York. 81-125.

4. Stiles, C. D., G. T. Capone, C. D. Scher, H. N. Antoniades, J. J. Van Wyk, and W. J. Pledger. 1979. Dual control of cell growth by somatomedins and platelet-derived growth factor. Proc. Natl. Acad. Sci. USA. 76:1279-1283.

5. Lawrence, W. T., J. A. Norton, M. B. Sporn, C. Gorschboth, and G. R. Grotendorst. 1986. The reversal of an adriamycin induced healing impairment with chemoattractants and growth factors. Ann. Surg. 203:142-147.

6. Lynch, S. E., J. C. Nixon, R. B. Colvin, and H. N. Antoniades. 1987. Role of platelet-derived growth factor in wound healing: synergistic effects with other growth factors. Proc. Natl. Acad. Sci. USA. 84:7696-7700.

7. Sporn, M. B., A. B. Roberts, L. M. Wakefield, and R. K. Assoian. 1986. Transforming growth factor beta: biological function and chemical structure. Science (Wash. DC). 233:532-534.

8. Wahl, S. M., D. A. Hunt, L. M. Wakefield, N. McCartneyFrancis, L. M. Wahl, A. B. Roberts, and M. B. Sporn. 1987. Transforming growth factor beta (TGF- $\beta$ ) induces monocyte chemotaxis and growth factor production. Proc. Natl. Acad. Sci. USA. 84:57885792.

9. Assoian, R. K., and M. B. Sporn. 1986. Type beta transforming growth factor in human platelets: release during platelet degranulation and action on vascular smooth muscle cells. J. Cell Biol. 102:12171223.

10. Roberts, A. B., M. A. Anzano, L. M. Wakefield, N. S. Roche, D. F. Stern, and M. B. Sporn. 1985. Type beta transforming growth factor: a bifunctional regulator of cellular growth. Proc. Natl. Acad. Sci. USA. 82:119-123.

11. Sporn, M. B., A. B. Roberts, J. H. Shull, J. M. Smith, J. M. Ward, and J. Sodek. 1983. Polypeptide transforming growth factors isolated from bovine sources and used for wound healing in vivo. Science (Wash. DC). 219:1329-1331.

12. Mustoe, T. A., G. F. Pierce, A. Thomason, P. Gramates, M. B. Sporn, and T. F. Deuel. 1987. Accelerated healing of incisional wounds in rats induced by transforming growth factor beta. Science (Wash. DC). 237:1333-1336.

13. Gospodarowicz, D., N. Ferrara, L. Schweigerer, and G. Neufeld. 1987. Structural characterization and biological functions of fibroblast growth factor. Endocrinol. Rev. 8:95-114.

14. Gospodarowicz, D., G. Neufeld, and L. S. Schweigerer. 1986. Fibroblast growth factor. Mol. Cell. Endocrinol. 46:187-204.

15. Folkman, J., and M. Klagsburn. 1987. Angiogenic factors. Science (Wash. DC). 235:442-447.

16. Pike, L. J., H. Marquardt, G. J. Todaro, B. Gallis, J. E. Casnellie, P. Bornstein, and E. G. Krebs. 1982. Transforming growth factor and epidermal growth factor stimulate the phosphorylation of a synthetic, tyrosine containing peptide in a similar manner. J. Biol. Chem. 257:14628-14631.

17. Niall, M., G. B. Ryan, and B. J. O'Brian. 1982. The effects of epidermal growth factor on wound healing in mice. J. Surg. Res. 33:164-169.

18. Brown, G. L., L. Curtsinger, J. R. Brightwell, D. M. Ackerman, G. R. Tobin, H. C. Polk, C. George-Nascimanto, P. Valenzuela, and G. S. Schultz. 1986. Enhancement of epidermal regeneration by biosynthetic epidermal growth factor. J. Exp. Med. 163:1319-1324.

19. Brightwell J. R., S. L. Riddle, R. A. Eiferman, P. Valenzuela, P. J. Barr, J. P. Merryweather, and G. S. Shultz. 1985. Biosynthetic human EGF accelerates healing of Neodecadron-treated primate corneas. Invest. Ophthalmol. Vis. Sci. 26:105-110.

20. Schultz, G. S., M. White, R. Mitchell, G. Brown, J. Lynch, D. R. Twardzik, and G. J. Todaro. 1987. Epithelial wound healing enhanced by transforming growth factor alpha and vaccinia growth factor. Science (Wash. DC). 235:350-352.

21. Buckley, A., J. M. Davidson, C. D. Kamerath, T. B. Wolt, and 
S. C. Woodward, 1985. Sustained release of epidermal growth factor accelerates wound repair. Proc. Natl. Acad. Sci. USA. 82:7340-7344.

22. Antoniades, H. N., C. P. Scher, and C. D. Stiles. 1979. Purification of the human platelet-derived growth factor. Proc. Natl. Acad. Sci. USA. 76:1809-1813.

23. Leof, E. B., J. J. Van Wyk, E. J. O'Keefe, and W. J. Pledger. 1983. Epidermal growth factor (EGF) is required only during the traverse of early G1 in PDGF stimulated density arrested BALB/c 3T3 cells. Exp. Cell. Res. 147:202-208.

24. Coffey, R. J. Jr., N. J. Sipes, C. C. Bascom, R. Graves-Deal, C. Y. Pennington, B. F. Weissman, and H. L. Moses. 1988. Growth modulation of mouse keratinocytes by transforming growth factors. Cancer Res. 48:1596-1602.

25. Switzer, B. R., and G. K. Summer. 1971. Improved method for hydroxyproline analysis in tissue hydrolysates. Anal. Biochem. 39:487-491.

26. Shipley, G. D., M. R. Pittelkow, J. J. Wille, R. E. Scott, and
H. L. Moses. 1986. Reversible inhibition of normal human prokeratinocyte proliferation by type beta transforming growth factor-growth inhibitor in serum-free medium. Cancer Res. 46:2068-2071.

27. Moses, H. L., R. F. Tucker, E. B. Leof, R. J. Coffey, J. Halper, and G. D. Shipley. 1985. Type beta transforming growth factor is a potent growth stimulator and growth inhibitor. Cancer Cells. 3:65-71.

28. Hockel, M., J. Sasse, and J. H. Wissler. 1987. Purified monocyte-derived angiogenic substance (Angiotropin) stimulates migration, phenotypic changes, and "tube formation" but not proliferation of capillary endothelial cells in vitro. J. Cell Physiol. 133:1-13.

29. Muller, G., J. Behrens, U. Nussbaumer, P. Bohlen, and W. Birchmeier. 1987. Inhibitory action of transforming growth factor beta on endothelial cells. Proc. Natl. Acad. Sci. USA. 84:5600-5604.

30. Graves, D. T., G. R. Grotendorst, H. N. Antoniades, C. J. Schwartz, and H. A. Valente. 1989. Platelet-derived growth factor is not chemotactic for human peripheral blood monocytes. Exp. Cell Res. 180:497-503. 